\title{
Intratumoral interleukin- 6 predicts ascites formation in patients with epithelial ovarian cancer: A potential tool for close monitoring
}

\author{
Samar Masoumi-Moghaddam ${ }^{1 *+}$, Afshin Amini ${ }^{1+}$, Ai-Qun Wei ${ }^{2}$, Gregory Robertson ${ }^{3}$ and David L. Morris ${ }^{1}$
}

\begin{abstract}
Background: The implication of IL-6 in the pathogenesis of epithelial ovarian cancer (EOC) is well documented. Accordingly, the clinicopathological significance of this cytokine in patients' ascites fluid or serum has largely been investigated. Since the main source of IL-6 secreted into the biological fluids is the tumor tissue, this study was designed to investigate the status and possible clinical relevance of the IL-6 expression in an array of EOC tissue specimens.

Methods: Tissue samples obtained from ninety-eight consecutive patients with EOC were studied using immunohistochemistry. Clinicopathological characteristics and treatment related factors were collected from patient files. The relationship between the expression of the protein of interest and the study endpoints of disease-free survival (DFS) and overall survival (OS) were analyzed using the Kaplan-Meier method. For evaluating the predictive value of IL-6, logistic regression and cox proportional hazards models were employed.

Results: An upregulation of IL-6 expression was observed in EOC tissues as compared with the normal samples $(p<0.0001)$. As regards the clinical relevance, IL-6 failed to predict OS, DFS and response to the platinum-based chemotherapy in EOC patients. In multivariate analysis, however, IL-6 was identified as an independent predictive factor for the development of post-treatment ascites (p:0.033).

Conclusions: Having the capability to predict the ascites formation, IL-6 might serve as a biomarker and a useful tool in EOC for monitoring purposes. IL-6 targeting for the prevention of the ascites development is a potential avenue for further investigation.
\end{abstract}

Keywords: Ascites, Chemorefractoriness, Disease free survival, Epithelial ovarian cancer, Interleukin-6, Overall survival

\section{Background}

Interleukin-6 (IL-6) is a classic pro-inflammatory cytokine associated with a variety of pathological conditions, including cancer. Evidence supports the role of IL-6 in the pathophysiology of epithelial ovarian cancer (EOC) where the presence of an immunosuppressive network protecting tumor from immune system is also involved in EOC growth and progression [1-3]. While contributing to the follicle development in normal ovaries and the regulation of chronic inflammation, IL- 6 can be involved

\footnotetext{
* Correspondence: samar.masoumi@gmail.com

${ }^{\dagger}$ Equal contributors

'Department of Surgery, St George Hospital, The University of New South

Wales, Gray Street, Kogarah, Sydney NSW 2217, Australia

Full list of author information is available at the end of the article
}

in the provision of a cellular microenvironment beneficial to cancer cell growth, proliferation, migration and survival. This can result from direct effects on tumor cell biology along with the regulation of the immune system components $[4,5]$. In vitro studies have confirmed the production of IL-6 by normal and neoplastic ovarian epithelium $[6,7]$. The association of IL-6 with EOC carcinogenesis and progression [8], as well as with the enhancement of EOC cell survival, resistance to chemotherapy [9] and invasiveness [10] has also been reported.

In the present study, we investigated the expression status of the intratumoral IL-6 in EOC tissue samples compared with normal ovarian tissue and evaluated a 
possible clinical relevance with regard to survival, response to the platinum-based chemotherapy and ascites formation. As a result, we observed a significant upregulation of IL-6 in the EOC tissue. Moreover, we identified IL-6 expression status of EOC tumor as an independent predictive biomarker for ascites formation in patients receiving adjuvant carbotaxol treatment.

\section{Patients and methods}

\section{Clinical cases and surgical samples}

Initially, institutional review board approval for this analysis was obtained from South Eastern Sydney and Illawarra Area Health Service Human Research Ethics Committee-Central Network (EC00135). Upon giving informed written consents, ninety-eight consecutive patients with primary epithelial ovarian cancer who had undergone standard surgical procedure (staging laparotomy/cytoreductive surgery) and adjuvant systemic chemotherapy (paclitaxel + carboplatin) between January 2001 and December 2012 at two specialized centers (St. George Hospital; St George Private Hospital, Sydney, Australia) were included in the study. A confirmatory review of pathology was performed. Ovarian neoplasms were histologically classified according to the World Health Organization (WHO) classification system [11]. The final staging of the disease was determined on the basis of a combination of surgical and pathological findings in accord with the Federation of Gynecology and Obstetrics (FIGO) guidelines [12]. Clinicopathological characteristics of the participants are shown in Table 1.

\section{Immunohistochemical staining}

For immunohistochemical study, five-micrometer sections were prepared from the paraffin blocks of the patients and immunostained as described previously [13]. Briefly, the sections were deparaffinized and incubated with $3 \%$ hydrogen peroxide and DAKO blocking buffer, subsequently. This was followed by overnight incubation at $4{ }^{\circ} \mathrm{C}$ with mouse monoclonal primary antibody (Santa Cruz) and then with appropriate secondary antibody using EnVision Plus kit (DAKO). The sections were then counterstained with hematoxylin. Tonsil tissue was used as the positive control. As regards the negative control, the same tissue as our positive control was used but the primary antibodies were replaced with the primary antibody diluents.

\section{Immunohistochemical scoring}

To evaluate the staining of the epithelial cells, a semiquantitative scoring method was performed according to Mattern et al. and Terris et al. [14, 15]. This scoring method enables the determination of both the intensity of the immunosignal and the percentage of cells showing positive staining. The percentage of positive cells was
Table 1 Clinicopathological characteristics of the participants

\begin{tabular}{|c|c|c|c|}
\hline \multicolumn{2}{|c|}{ Characteristic } & \multirow{2}{*}{$\begin{array}{l}\text { Categorization } \\
\leq 50\end{array}$} & \multirow{2}{*}{$\begin{array}{l}\text { Patients }(n=98) \\
16\end{array}$} \\
\hline Age (years) & Range: $35-84$ & & \\
\hline & Median: 62 & $>50$ & 82 \\
\hline \multirow{7}{*}{\multicolumn{2}{|c|}{ Histological subtype }} & High-grade serous & 63 \\
\hline & & Low-grade serous & 17 \\
\hline & & High-grade endometrioid & 1 \\
\hline & & Low-grade endometrioid & 2 \\
\hline & & Mucinous & 2 \\
\hline & & Clear cell & 5 \\
\hline & & Others & 8 \\
\hline \multirow{2}{*}{\multicolumn{2}{|c|}{ FIGO stage }} & $|-| \mid$ & 14 \\
\hline & & $\mathrm{III-IV}$ & 84 \\
\hline \multirow{4}{*}{\multicolumn{2}{|c|}{ Extent of residual tumour }} & None & 46 \\
\hline & & $<1 \mathrm{~cm}$ & 35 \\
\hline & & $1-2 \mathrm{~cm}$ & 0 \\
\hline & & $>2 \mathrm{~cm}$ & 17 \\
\hline \multirow{2}{*}{\multicolumn{2}{|c|}{$\begin{array}{l}\text { Clinical response to } \\
\text { platinum chemotherapy }\end{array}$}} & Sensitive & 77 \\
\hline & & Resistant & 21 \\
\hline \multirow{2}{*}{\multicolumn{2}{|c|}{ post-treatment ascites }} & Yes & 40 \\
\hline & & No & 58 \\
\hline
\end{tabular}

scored as: no positive cells (0); $1-25 \%$ (1); $26-50 \%$ (2); and $50 \%>(3)$. The intensity of the staining was scored as: no staining (0); weak (1); moderate (2); strong (3). Following the evaluation by two observers blinded to patient outcome, the immunohistochemical score was calculated as follows, yielding a range of values between 0 and 9: immunohistochemical score $=$ [percentage of positive cells] $\times$ [intensity of staining].

\section{Statistical analysis}

All statistical analyses were conducted using the statistical package SPSS, version 22 (SPSS Inc., USA). Student $t$-test was used for comparing the actual difference between two means. Spearman correlation coefficient testing was performed to evaluate the associations between the clinicopathological parameters and the expression of IL-6. The binary cut-off point was identified using the Classification and Regression Tree (CART) algorithm. According to the cut-off point determined, the immunohistochemical scores were classified as either low (score $\leq$ 3.5 ) or high (score > 3.5). The relationship between the IL6 expression and the study endpoints of disease-free survival (DFS) and overall survival (OS) were individually analyzed using the Kaplan-Meier method. Univariate and multivariate logistic regression analyses were conducted to ascertain the effect of the studied cytokine and other clinicopathological variables on the likelihood of the development of post-treatment ascites or chemotherapy 
refractory disease. A p value of $<0.05$ was considered statistically significant for all analyses.

\section{Results}

\section{EOC tumors express higher levels of IL-6}

Comparing the expression status of IL-6 in EOC tissues with that in normal samples, we found significantly higher levels of the IL-6 expression in tumor tissues $(p<0.0001)$. Mean expression scores were $3.35 \pm 0.15$ and $1.15 \pm 0.15$ for tumor and normal biopsies, respectively. When the IL6 immunohistochemical scores of matched normal and cancer tissues were compared, we observed higher levels of the IL-6 expression in seventy-five percent of tumor tissues (Fig. 1).

\section{IL-6 predicts development of post-treatment ascites}

In our cohort, while 35 cases had no history of ascites either at the time of diagnosis or after treatment, ascites was present in 63 patients. Mean IL-6 expression scores in the ascites group $(3.59 \pm 0.19)$ were significantly higher than those in the non-ascites group ( $2.91 \pm 0.24$, p:0.039). Subgroup analysis did not indicate a statistically significant difference in mean IL-6 expression scores between patients who had ascites at the time of diagnosis (3.56 $\pm 0.22)$ and those without ascites (3.11 $\pm 0.21, \mathrm{p}: 0.154)$. On the other hand, the comparison of mean IL- 6 expression scores between patients who did and did not develop ascites after treatment $(3.85 \pm 0.26$ and $3.00 \pm$ 0.18 , respectively) revealed significantly higher levels of IL-6 expression in the ascites positive group (p:0.007). When the association between the expression of IL-6 and the history of ascites was evaluated, a direct significant correlation was found between the IL- 6 expression and post-treatment ascites formation ( $\mathrm{p}: 0.034$, correlation coefficient $=0.214$ ).

The predictive value of IL- 6 expression with regard to the development of post-treatment ascites was further evaluated employing logistic regression analysis. Univariate test revealed the significance of the IL-6 expression for predicting the development of post-treatment ascites

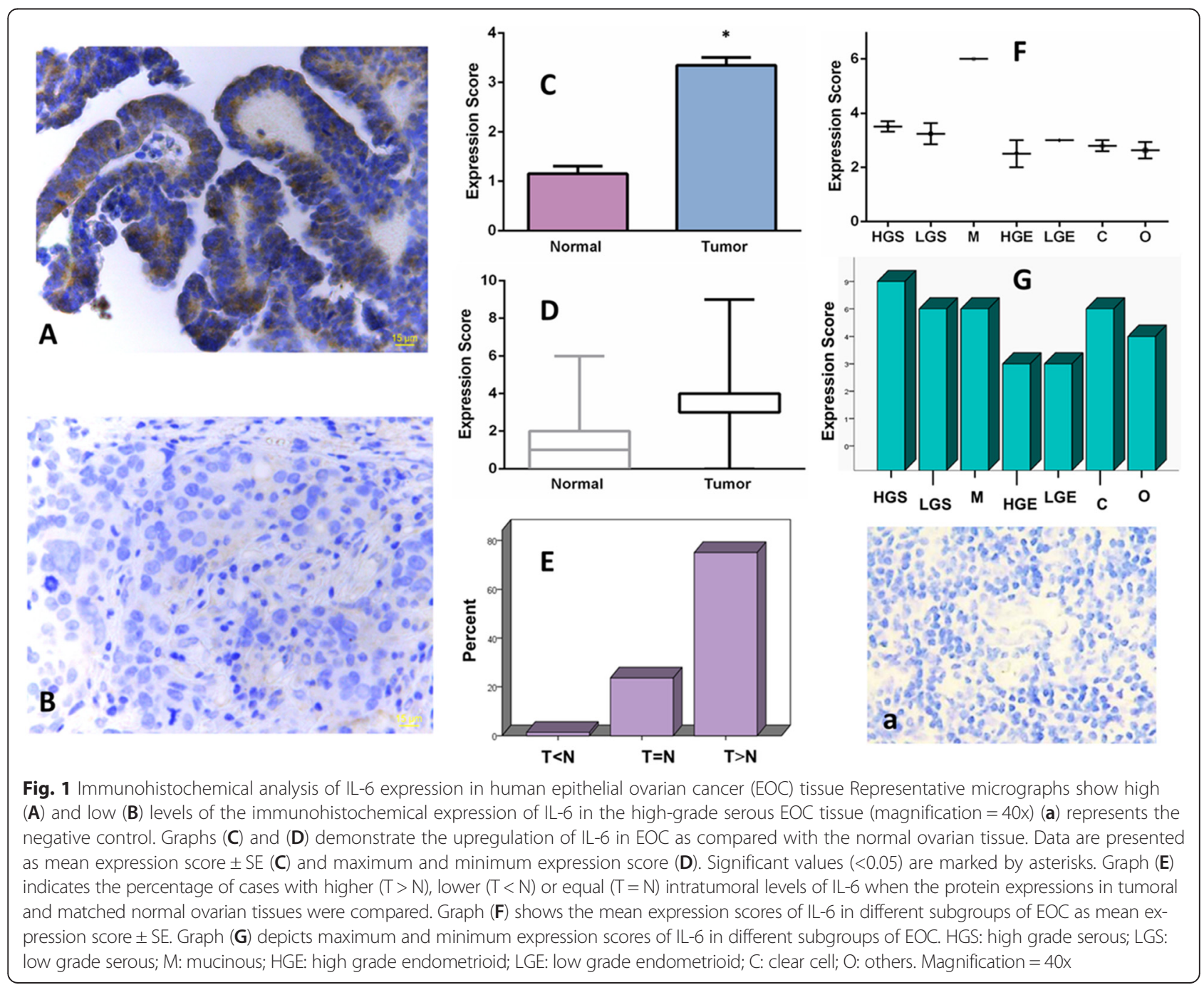


$(H R=0.39 ; 95 \% \mathrm{CI}, 0.16-0.94 ; \mathrm{p} 0.036)$. Stage $(H R=0.08$; $95 \% \mathrm{CI}, 0.01-0.67 ; \mathrm{p}: 0.020)$, ascites at diagnosis $(H R=$ 0.23; $95 \%$ CI, 0.09-0.55; p:0.001) and refractory disease $(H R=0.15 ; 95 \% \mathrm{CI}, 0.05-0.46 ; \mathrm{p}: 0.001)$ also appeared to be of predicting value among other clinicopathological features. In multivariate logistic regression analysis, IL-6 $(H R=0.31 ; 95 \% \mathrm{CI}, 0.10-0.91 ; \mathrm{p}: 0.033)$, ascites at diagnosis $(H R=0.22 ; 95 \% \mathrm{CI}, 0.07-0.66$; p:0.007) and refractory disease $(H R=0.09 ; 95 \% \mathrm{CI}, 0.02-0.36$; $\mathrm{p}: 0.001)$ retained their values as independent predictors of post-treatment ascites in EOC patients whereas stage (p:0 .075) failed to show an independent predictive value.

\section{IL-6 has no predictive value for overall survival and disease free survival}

In the statistical analysis of overall survival (OS), the difference in median OS of IL-6 high- and low-expressing groups (3.8 and 3.9 years, respectively) as well as in mean OS of these two groups (4.7 and 5.3 years, respectively) was not statistically significant (p:0.646). With respect to disease free survival (DFS) of IL-6 high- and lowexpressing groups, there was no statistically meaningful difference (p:0.30) between the median (22 vs 30 months, respectively) or mean values (41.5 vs 50 months, respectively) of the two groups, either. Cox analysis of the results consistently failed to show a predictive value for IL-6 with regard to survival (OS, p:0.646; DFS, p:0.301).

\section{IL-6 does not predict platinum-based refractory disease}

Finally, we investigated whether the expression status of IL-6 in surgical specimens has the potential to predict response to the platinum-based chemotherapy. When patients who later showed resistance to carbotaxol chemotherapy were accordingly compared with those who remained sensitive to the same regimens, mean IL-6 expression scores of the refractory (3.19) and sensitive (3.39) groups turned out to be similar ( $\mathrm{p}: 0.605)$. Our logistic regression analysis consistently demonstrated that IL-6 expression fails to predict response to the platinum-based treatment (p:0.760).

\section{Discussion}

IL-6 is known as a pleotropic cytokine implicated in EOC carcinogenesis. It influences EOC growth and development through direct and indirect effects on tumor cells or their microenvironment, respectively [4, 5]. As such, IL- 6 has been indicated to promote EOC cell proliferation, migration, invasion, survival and resistance to chemotherapeutic agents $[9,10,16]$. Reports show that IL-6 contributes to the development of EOC-induced malignant ascites [8]. Here, we demonstrated that IL-6 was expressed at higher levels in human EOC tissues than in normal ovarian tissues. In agreement, increased tumoral expression [17] and high serum [18, 19] or ascetic [20] levels of IL-6 have been reported in patients with EOC. Accordingly, clinicopathological relevance of intratumoral, serum or ascitic IL-6 in EOC has been investigated [18-25]. Plewka et al. [26] observed that malignant serous tumors had higher expression levels of IL-6 as compared with serous borderline and benign lesions. Guo et al. [27] reported a significant difference in immunohistochemical expressions of IL-6 among the metastatic, drug-resistant recurrent tumors, and matched primary tumors, with more staining density and positivity observed in the drug-resistant and metastatic tumors. In another study by Coward et al. [28], intensity of IL-6 staining in malignant cells was found to be significantly associated with poor prognosis. Similarly, a link between high levels of serum or ascitic IL- 6 and unfavorable clinical outcome has been reported. In this regard, serum IL-6 has shown significant association with tumor burden, clinical disease status, and survival $[21,22]$, as well as prognostic value [25], in EOC. In a study by Scambia et al. [29], higher levels of serum IL- 6 was found in patients unresponsive to chemotherapy. In line with these findings, Cohen et al. [30] found that cisplatin treatment of EOC cells upregulated IL-6, and IL-6 inhibition, on the other hand, resulted in significant sensitization to cisplatin, suggesting that IL- 6 could contribute to the induction of platinum resistance in EOC. In agreement, Wang et al. found that both exogenous and endogenous IL- 6 could induce cisplatin and paclitaxel resistance in vitro via increased expression of both multidrug resistance-related genes and apoptosis inhibitory proteins, as well as activation of extracellular signal-regulated kinases (ERK) and Akt signaling [9]. They also demonstrated that IL-6 might contribute to the refractoriness of EOC to tamoxifen [31]. In our study, however, intratumoral IL-6 showed neither dependent nor independent predicting value for OS, DFS or response to the platinum-based chemotherapy. In line with our results, Plante el al [20] indicated that serum and ascites IL-6 levels did not correlate statistically with OS. In contrast to our observation, where almost equal intratumoral IL-6 levels were detected in platinum-based resistant and sensitive cases, they reported lower ascitic IL-6 in patients who responded to chemotherapy, although the difference was not found to be statistically significant.

In EOC, ascites is present in at least one third of patients and is believed to contribute to the spread of cancer to secondary sites [32], as well as to peritoneal dissemination [33]. Interestingly, the predictive value of IL- 6 for the development of post-treatment ascites was observed in the present study. In line with our findings, Plante el al [20] reported a direct association between ascitic IL- 6 and ascites volume. In agreement, Lo et al. [8] described an IL-6 trans-signaling pathway in formation and progression of 
ascites in EOC wherein IL-6 and its soluble IL-6 receptor (IL-6R $\alpha$ ) serve as an important regulator of endothelial cell survival, migration, and integrity, and IL-6 trans-signaling on endothelial cells prevents chemotherapy-induced apoptosis, induces endothelial hyperpermeability, and increases transendothelial migration of ovarian cancer cells, contributing to ascites formation and tumor progression.

Future clinical investigations are needed to establish improved clinical evidence to guide patient care in EOC. With respect to the results from the present study, these investigations could be developed at two levels: 1) the assessment of the effectiveness of IL-6 as a tool for posttreatment monitoring of EOC patients, alone or in combination with current biomarkers in use; 2) the evaluation of IL- 6 as a potential target in the treatment of EOC. With regard to its value as a potential target for developing novel treatment strategies, our laboratory has previously studied the inhibitory effects of minocycline on IL-6 production in EOC. It was shown in in vivo models of EOC that orally administered minocycline was highly effective in decreasing tumor burden and suppressing ovarian cancer-induced malignant ascites by targeting IL-6 [34].

\section{Conclusions}

Here, we report the upregulation of IL-6 in EOC, with predictive value for development of ascites following the platinum-based treatment. In keeping with results from previous studies, our findings highlight the role of this cytokine in EOC patients which needs to be further explored in future research.

\section{Abbreviations \\ DFS: Disease-free survival; EOC: Epithelial ovarian cancer; IL-6: Interleukin-6; OS: Overall survival.}

\section{Competing interests}

The authors declare that they have no competing interests.

\section{Authors' contributions}

SMM and AA designed the study, carried out the experiments, performed data interpretation and statistical analysis, and prepared the manuscript. AQW and GR reviewed manuscript. DLM provided the study concept, contributed to quality control of data and reviewed the manuscript. All authors read and approved the final manuscript.

\section{Author details \\ ${ }^{1}$ Department of Surgery, St George Hospital, The University of New South Wales, Gray Street, Kogarah, Sydney NSW 2217, Australia. ${ }^{2}$ Department of Orthopedic Surgery, St. George Hospital, The University of New South Wales, Gray Street, Kogarah, Sydney NSW 2217, Australia. ${ }^{3}$ Department of Gynecology Oncology, St George Hospital, The University of New South Wales, Gray Street, Kogarah, Sydney NSW 2217, Australia.}

Received: 2 June 2015 Accepted: 29 July 2015

Published online: 19 August 2015

\section{References}

1. Kulbe H, Chakravarty P, Leinster DA, Charles KA, Kwong J, Thompson RG, et al. A dynamic inflammatory cytokine network in the human ovarian cancer microenvironment. Cancer Res. 2012;72(1):66-75. doi:10.1158/00085472.can-11-2178.
2. Longuespee R, Boyon C, Desmons A, Vinatier D, Leblanc E, Farre I, et al. Ovarian cancer molecular pathology. Cancer Metastasis Rev. 2012;31(3-4):713-32. doi:10.1007/s10555-012-9383-7.

3. Matte I, Lane D, Laplante C, Rancourt C, Piche A. Profiling of cytokines in human epithelial ovarian cancer ascites. Am J Cancer Res. 2012;2(5):566-80.

4. Heikkila K, Ebrahim S, Lawlor DA. Systematic review of the association between circulating interleukin-6 (IL-6) and cancer. Eur J Cancer. 2008:44(7):937-45. doi:10.1016/j.ejca.2008.02.047.

5. Nash MA, Ferrandina G, Gordinier M, Loercher A, Freedman RS. The role of cytokines in both the normal and malignant ovary. Endocrine-Related Cancer. 1999;6(1):93-107.

6. Lidor YJ, Xu FJ, Martinez-Maza O, Olt GJ, Marks JR, Berchuck A, et al. Constitutive production of macrophage colony-stimulating factor and interleukin- 6 by human ovarian surface epithelial cells. Exp Cell Res. 1993;207(2):332-9. doi:10.1006/excr.1993.1200.

7. Watson JM, Berek JS, Martinez-Maza O. Growth inhibition of ovarian cancer cells induced by antisense IL-6 oligonucleotides. Gynecol Oncol. 1993;49(1):8-15. doi:10.1006/gyno.1993.1077.

8. Lo CW, Chen MW, Hsiao M, Wang S, Chen CA, Hsiao SM, et al. IL-6 transsignaling in formation and progression of malignant ascites in ovarian cancer. Cancer Res. 2011;71(2):424-34. doi:10.1158/0008-5472.can-10-1496.

9. Wang Y, Niu XL, Qu Y, Wu J, Zhu YQ, Sun WJ, et al. Autocrine production of interleukin- 6 confers cisplatin and paclitaxel resistance in ovarian cancer cells. Cancer Lett. 2010;295(1):110-23. doi:10.1016/j.canlet.2010.02.019.

10. Obata NH, Tamakoshi K, Shibata K, Kikkawa F, Tomoda Y. Effects of interleukin-6 on in vitro cell attachment, migration and invasion of human ovarian carcinoma. Anticancer Res. 1997;17(1A):337-42.

11. Chen WW, Ruiz B, Killeen JL, Coté TR, Wu XC, Correa CN, et al. Pathology and classification of ovarian tumors. Cancer. 2003;97(S10):2631-42. doi:10.1002/cncr.11345.

12. Odicino F, Pecorelli S, Zigliani L, Creasman WT. History of the FIGO cancer staging system. Int J Gynaecology Obstetrics. 2008;101(2):205-10. doi:10.1016/j.jijgo.2007.11.004.

13. Masoumi-Moghaddam S, Amini A, Wei AQ, Robertson G, Morris DL. Sprouty 2 protein, but not Sprouty 4 , is an independent prognostic biomarker for human epithelial ovarian cancer. Int J Cancer. 2015;137(3):560-70. doi:10.1002/ijc.29425.

14. Mattern J, Koomagi R, Volm M. Association of vascular endothelial growth factor expression with intratumoral microvessel density and tumour cell proliferation in human epidermoid lung carcinoma. Br J Cancer. 1996;73(7):931-4.

15. Terris B, Scoazec JY, Rubbia L, Bregeaud L, Pepper MS, Ruszniewski P, et al. Expression of vascular endothelial growth factor in digestive neuroendocrine tumours. Histopathology. 1998;32(2):133-8.

16. Wang Y, Li L, Guo X, Jin X, Sun W, Zhang X, et al. Interleukin-6 signaling regulates anchorage-independent growth, proliferation, adhesion and invasion in human ovarian cancer cells. Cytokine. 2012;59(2):228-36. doi:10.1016/j.cyto.2012.04.020.

17. Glezerman M, Mazot M, Maymon E, Piura B, Prinsloo I, Benharroch D, et al. Tumor necrosis factor-alpha and interleukin- 6 are differently expressed by fresh human cancerous ovarian tissue and primary cell lines. Eur Cytokine Netw. 1998:9(2):171-9.

18. Acien P, Ortola C, Barbal A, Quereda F, Dosda MD, Mauri M, et al. Comparative study of the diagnostic value of several tumor markers and hormonal determinations in ovarian neoplasms. Progresos en Obstetricia y Ginecologia. 1994;37(3):163-70.

19. Gorelik E, Landsittel DP, Marrangoni AM, Modugno F, Velikokhatnaya L, Winans MT, et al. Multiplexed immunobead-based cytokine profiling for early detection of ovarian cancer. Cancer Epidemiol Biomarkers Prev. 2005;14(4):981-7. doi:10.1158/1055-9965.epi-04-0404.

20. Plante M, Rubin SC, Wong GY, Federici MG, Finstad CL, Gastl GA. Interleukin-6 level in serum and ascites as a prognostic factor in patients with epithelial ovarian cancer. Cancer. 1994;73(7):1882-8.

21. Berek JS, Chung C, Kaldi K, Watson JM, Knox RM, Martinez-Maza O. Serum interleukin-6 levels correlate with disease status in patients with epithelial ovarian cancer. Am J Obstet Gynecol. 1991;164(4):1038-42. discussion 42-3.

22. Dobrzycka B, Mackowiak-Matejczyk B, Terlikowska KM, Kulesza-Bronczyk B, Kinalski M, Terlikowski SJ. Serum levels of IL-6, IL-8 and CRP as prognostic factors in epithelial ovarian cancer. Eur Cytokine Netw. 2013;24(3):106-13. doi:10.1684/ecn.2013.0340.

23. Kryczek I, Grybos M, Karabon L, Klimczak A, Lange A. IL-6 production in ovarian carcinoma is associated with histiotype and biological 
characteristics of the tumour and influences local immunity. Br J Cancer. 2000;82(3):621-8. doi:10.1054/bjoc.1999.0973.

24. Kutteh WH, Kutteh CC. Quantitation of tumor necrosis factor-alpha, interleukin-1 beta, and interleukin-6 in the effusions of ovarian epithelial neoplasms. Am J Obstet Gynecol. 1992;167(6):1864-9.

25. Scambia G, Testa U, Benedetti Panici P, Foti E, Martucci R, Gadducci A, et al. Prognostic significance of interleukin 6 serum levels in patients with ovarian cancer. Br J Cancer. 1995;71(2):354-6.

26. Plewka D, Kowalczyk AE, Jakubiec-Bartnik B, Morek M, Bogunia E, Kmiec A, et al. Immunohistochemical visualization of pro-inflammatory cytokines and enzymes in ovarian tumors. Folia Histochem Cytobiol. 2014;52(2):124-37. doi:10.5603/fhc.2014.0015.

27. Guo YQ, Lu P, Duan ZF, Zhang Z. Effects of siltuximab on the interleukin-6/ Stat3 signaling pathway in ovarian cancer. Zhonghua Fu Chan Ke Za Zhi. 2010;45(11):854-9.

28. Coward J, Kulbe H, Chakravarty P, Leader D, Vassileva V, Leinster DA, et al. Interleukin-6 as a therapeutic target in human ovarian cancer. Clin Cancer Res. 2011;17(18):6083-96. doi:10.1158/1078-0432.ccr-11-0945.

29. Scambia G, Testa U, Panici PB, Martucci R, Foti E, Petrini M, et al. Interleukin-6 serum levels in patients with gynecological tumors. Int J Cancer. 1994:57(3):318-23.

30. Cohen S, Bruchim I, Graiver D, Evron Z, Oron-Karni V, Pasmanik-Chor M, et al. Platinum-resistance in ovarian cancer cells is mediated by IL-6 secretion via the increased expression of its target cIAP-2. J Molec Med (Berlin, Germany). 2013;91(3):357-68. doi:10.1007/s00109-012-0946-4.

31. Wang Y, Qu Y, Zhang XL, Xing J, Niu XL, Chen X, et al. Autocrine production of interleukin-6 confers ovarian cancer cells resistance to tamoxifen via ER isoforms and SRC-1. Mol Cell Endocrinol. 2014;382(2):791-803. doi:10.1016/j.mce.2013.10.029.

32. Puiffe ML, Le Page C, Filali-Mouhim A, Zietarska M, Ouellet , Tonin PN, et al. Characterization of ovarian cancer ascites on cell invasion, proliferation, spheroid formation, and gene expression in an in vitro model of epithelial ovarian cancer. Neoplasia (New York, NY). 2007:9(10):820-9.

33. Carmignani $C P$, Sugarbaker TA, Bromley CM, Sugarbaker PH. Intraperitoneal cancer dissemination: mechanisms of the patterns of spread. Cancer Metastasis Rev. 2003;22(4):465-72.

34. Pourgholami MH, Ataie-Kachoie P, Badar S, Morris DL. Minocycline inhibits malignant ascites of ovarian cancer through targeting multiple signaling pathways. Gynecol Oncol. 2013;129(1):113-9. doi:10.1016/j.ygyno.2012.12.031.

\section{Submit your next manuscript to BioMed Central and take full advantage of:}

- Convenient online submission

- Thorough peer review

- No space constraints or color figure charges

- Immediate publication on acceptance

- Inclusion in PubMed, CAS, Scopus and Google Scholar

- Research which is freely available for redistribution

Submit your manuscript at www.biomedcentral.com/submit 